\title{
Relationship between single-nucleotide polymorphisms in un-translated region of human leukocyte antigen-G and preeclampsia
}

\author{
Zhang Zhan', Zhang Nan', Zhang Linlin², Jia Liting ${ }^{2}$ and Li Hong ${ }^{1}$ \\ ${ }^{1}$ Department of Obstetrics and Gynecology, ${ }^{2}$ Department of Clinical Laboratory, The Third Affiliated Hospital of Zhengzhou \\ University, Zhengzhou City, Henan Province, China
}

*For correspondence: Email: zhanzhang_zz@163.com; Tel: +86 13837362662

Sent for review: 25 January 2017

Revised accepted: 11 June 2017

\begin{abstract}
Purpose: The aim of this study was to unravel the link between human leukocyte antigen-G untranslated region (HLA-G 3-UTR) single-nucleotide polymorphism (SNP) and preeclampsia by examining polymorphisms in HLA-G 3-UTR in preeclampsia patients and their newborns, as well as those of women with normal pregnancy and their newborns.

Methods: Single pregnant mothers and their newborns at the Third Affiliated Hospital of Zhengzhou University, China, were divided into preeclampsia group (144 cases), and normal pregnancy group (122 cases). Blood samples from the two groups were collected for DNA extraction, and the DNA samples were analyzed for HLA-G 3'-UTR SNP by polymerase chain reaction (RT-PCR) and direct sequencing method.

Results: The frequency of CG genotype in HLA-G 3-UTR 3127 gene in the preeclampsia group was significantly lower, while the frequency of AA genotype in HLA-G 3-UTR 3172 gene in the preeclampsia group was significantly higher $(p<0.05)$ when compared with the normal pregnancy group. Furthermore, frequencies of the compatible genotype AA/AA (mothers/newborns) in HLA-G 3-UTR 3172 gene in the preeclampsia group were significantly higher relative to the normal pregnancy group ( $p<$ 0.05).

Conclusion: These results suggest that when CC/GG is the compatible genotype in HLA-G 3-UTR 3127 gene of mothers/newborns, preeclampsia risk may decrease, but it may increase if the compatible genotype is AA/AA. Thus, SNP in HLA-G 3-UTR 3127 gene may be a protective factor against preeclampsia in Chinese Han pregnant women, while SNP in 3172 gene may be associated with susceptibility to preeclampsia.
\end{abstract}

Keywords: Single-nucleotide polymorphisms, Human leukocyte antigen-G, Un-translated Region, Preeclampsia

Tropical Journal of Pharmaceutical Research is indexed by Science Citation Index (SciSearch), Scopus, International Pharmaceutical Abstract, Chemical Abstracts, Embase, Index Copernicus, EBSCO, African Index Medicus, JournalSeek, Journal Citation Reports/Science Edition, Directory of Open Access Journals (DOAJ), African Journal Online, Bioline International, Open-J-Gate and Pharmacy Abstracts

\section{INTRODUCTION}

Preeclampsia is a hypertensive disorder in pregnancy, a multiple organ dysfunction of pregnant women during the second and third trimesters of pregnancy. It is characterized by hypertension, proteinuria and edema 20 weeks into pregnancy. The incidence of stroke in China is $9.4 \%$, while in foreign countries it ranges from 7 to $12 \%$ [1]. Preeclampsia is a major contributory factor to pre-natal morbidity and mortality $[2,3]$. 
The pathogenesis of preeclampsia has been attributed to different factors. Studies on preeclampsia within and outside China have tended to focus on factors such as genetic susceptibility, immune mal-adaptation, placental ischemia and oxidative stress [4]. One of the most popular hypotheses posits a relationship between the pathogenesis of preeclampsia and abnormal immune tolerance $[5,6]$. Some scholars believe that the embryo carries paternal gene. Thus the embryo is homologous graft for mother, resulting in an immune reaction between embryo and mother [7]. Other researchers are of the view that immune tolerance can protect the embryo as a homologous graft from rejection by the maternal immune system $[3,8]$. In early pregnancy, trophoblast cells may invade the myometrium and spiral artery without being identified and excluded by the maternal immune system. This is associated with MHC expressed in trophoblast cells. Human leukocyte antigen (HLA-G) which belongs to non-classical MHC-I molecules in humans, are highly expressed in maternal-fetal extra-villous cytotrophoblast (EVCT). HLA-G occupies a crucial place in maternal-fetal immune tolerance and the rebuilding of placental vessels $[5,9,10]$.

Polymorphism has been proven in the noncoding and coding regions of HLA-G. The polymorphism in non-coding region of HLA-G includes polymorphism in 3-untranslated region (3-UTR) and 5-upstream regulatory region (5URR). Much attention has been focused in recent years on the study of 3-UTR polymorphisms.

Research on pregnant women has found a single-nucleotide polymorphism (SNP) in HLA-G 3-UTR involving mutation of normal $\mathrm{G}$ in 3172 to A [11]. It is believed that 3172 SNP polymorphism may be associated with preeclampsia, and may be involved in stabilization of HLA-G mRNA. Studies on newborns showed that this polymorphism is associated with severe preeclampsia when the neonatal genotype is SNP 2995 (C) / SNP3127 (G) / SNP3127 (A) / SNP3181 (G) / +14 base pair (bp) homozygote. Irrespective of pregnancy status (i.e. normal pregnancy or preeclampsia), the results were attributed to mother-baby gene interaction. Thus it would not be comprehensive enough to limit pathogenesis of preeclampsia to mother or embryo; a more comprehensive study of the pathogenesis must focus on compatible genotype of both sides by analyzing mother-baby gene interaction. This is due to the fact that interaction between mother and embryo may influence the status of pregnancy. The present study was aimed at a more comprehensive approach to the pathogenesis of preeclampsia from the relationship between HLA-G polymorphism and preeclampsia based on genotype compatibility between mother and embryo.

\section{METHODS}

\section{Study subjects}

From October 2008 to November 2010, pregnant women with single embryo, who were attended to in the Department of Obstetrics and Gynecology at the Third Affiliated Hospital of Zhengzhou University, China, were selected for the study. These women were randomly divided into two groups: preeclampsia group (case group) and normal pregnancy group (control group).There were 144 cases of pregnant women and their newborns in the preeclampsia group. The mean age of the pregnant women was $31.40 \pm 1.76 y e a r s$, and the mean gestational period was $34.85 \pm 5.14$ weeks. In the normal pregnancy group, there were 122 cases of pregnant women and their newborns. The mean age of the pregnant women was $31.39 \pm 4.2$ years, while the mean gestational period was $37.46 \pm 1.98$ weeks. There were significant differences between two groups with respect to age, pregnancy time, gestational period and delivery time $(p<0.05)$. The pregnant women in both groups were Han residents with no consanguinity and no history of inter-marriage. All of the subjects in the study were monitored for 12 weeks after delivery. Based on the declaration of Helsinki promulgated in 1964 as amended in 1996 [12], this study was approved by the Ethical Committee of The Third Affiliated Hospital of Zhengzhou University (approval no. 20100312).

\section{Choice of standard}

The inclusive criteria of control group were: full term pregnancies, blood pressure lower than $140 / 90 \mathrm{~mm} \mathrm{Hg}$ and absence of proteinuria. There were no cases of high blood pressure, heart disease, kidney disease, liver disease and diabetes in pregnant women in the two groupss. In addition, they had no history of blood transfusions, immunization, or any complications of pregnancy. All the pregnant women were monitored for 12 weeks after delivery.

\section{DNA extraction}

Genomic DNA was extracted from white blood cells obtained from peripheral venous blood ( $2 \mathrm{~mL}$ of cord blood of pregnant women and their embryo from the two groups). Extraction of 
genomic DNA was carried out using a commercial kit.

\section{Expansion of targeted fragments and genetic sequencing}

\section{Primers: primer sequence}

The primer sequences are shown in Table 1.

\section{System and reaction conditions}

The targeted fragments were amplified by Nested polymerase chain reaction (nPCR. The PCR reaction conditions were: pre-denaturation at $95^{\circ} \mathrm{C}$ for $5 \mathrm{~min}$, denaturation at $95^{\circ} \mathrm{C}$ for $30 \mathrm{~s}$, annealing at $68^{\circ} \mathrm{C}$ for $30 \mathrm{~s}$, extended at $72^{\circ} \mathrm{C}$ for $1 \mathrm{~min}$, a total of 36 cycles, and finally extended at $72^{\circ} \mathrm{C}$ for $10 \mathrm{~min}$. The PCR products of HLA-G 3UTR were subjected to $2 \%$ agarose electrophoresis to comply with the requirements of the experimental design (Plate 1).

The first lane is the marker. The second to seventh lanes are 6 aimed genes which were chosen at random (245bp).

\section{Sequencing}

Fragments of PCR amplification product 245bp and 3 SNPs were discovered from the resultant sequence. These three different SNPs are located in 3127 site, 3172 site and 3181 site, which lie in HLA-G exon 8 3-UTR. The PCR products were sequenced by reverse sequencing. The tables of sequence obtained were reverse and complementary sequences, which meant that the site in $T$ peak should be interpreted as $A$, and the site in $G$ peak should be interpreted as $C$. The tables of sequence from each SNP site in HLA-G gene are shown in Figure 1.

\section{Statistics}

Software SPSS 16.0 was used to analyze all data to determine if the genotypic distribution was in Hardy-Weinberg equilibrium. For analysis of measurement data, t-test was used to compare the two groups. Non-normal distribution measurement data were compared with rank sum test. Differences in genotype distribution were tested by Chi-Square test method of Fourfold table where $n \geq 40$ and theoretical frequency $(T) \geq 5$; ordinary Chi-Square test was used where $n \geq 40$ but $1 \leq T<5$, corrective ChiSquare test was used; where $n<40$ or $T<1$, Fisher definite probability method was employed. Testing standard taken was $\alpha=0.05$.

\section{RESULTS}

Results of analysis of SNP genotype frequency distributions of HLA-G 3-UTR in pregnant women and embryos from the preeclampsia and normal pregnancy groups satisfied the law of HardyWeinberg equilibrium $(p>0.05)$. Thus the method is suitable for analysis of HLA-G 3-UTR SNP genotype distributions. The study showed that in HLA-G 3-UTR, three single-nucleotide polymorphisms in HLA-G 3-UTR occurred at site 3127 (rs1063320, $\mathrm{C} \rightarrow \mathrm{G}$ ); site 3172 site $(\mathrm{rs} 9380142, \quad \mathrm{G} \rightarrow \mathrm{A}), \quad$ and site 3181 site $(\mathrm{rs} 1610696, \mathrm{C} \rightarrow \mathrm{G})$.

Table 1: PCR primer sequence of genes

\begin{tabular}{lcc}
\hline Gene & Primer sequence & Amplification products \\
\hline HLA-G 3-UTR Primers & GGGATGTCTCCGTCTCTGTC & 245 \\
Upstream & GGGATGTCTCCGTCTCTGTC & \\
Downstream & & 548 \\
$\begin{array}{l}\text {-actin } \\
\text { Upstream }\end{array}$ & GTGGGGCGCCCCAGGCACCA & \\
Downstream & GTCCTTAATGTCACGCACGATTTC & \\
\hline
\end{tabular}

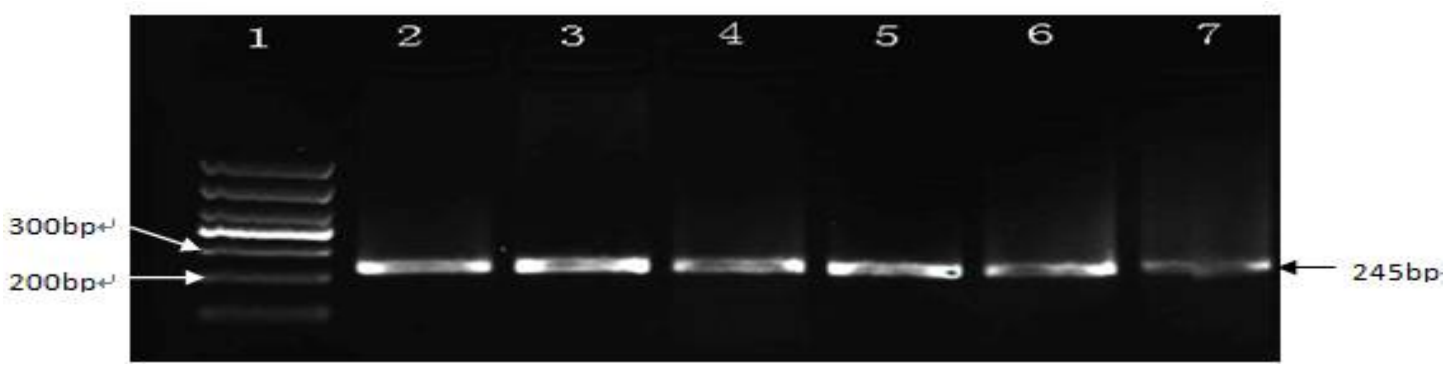

Plate 1: Amplification products of HLA-G 3-UTR SNP and the results of agarose electrophoresis. 1st lane: Marker; 2nd-7th lanes: aimed genes chosen at random (245bp) 


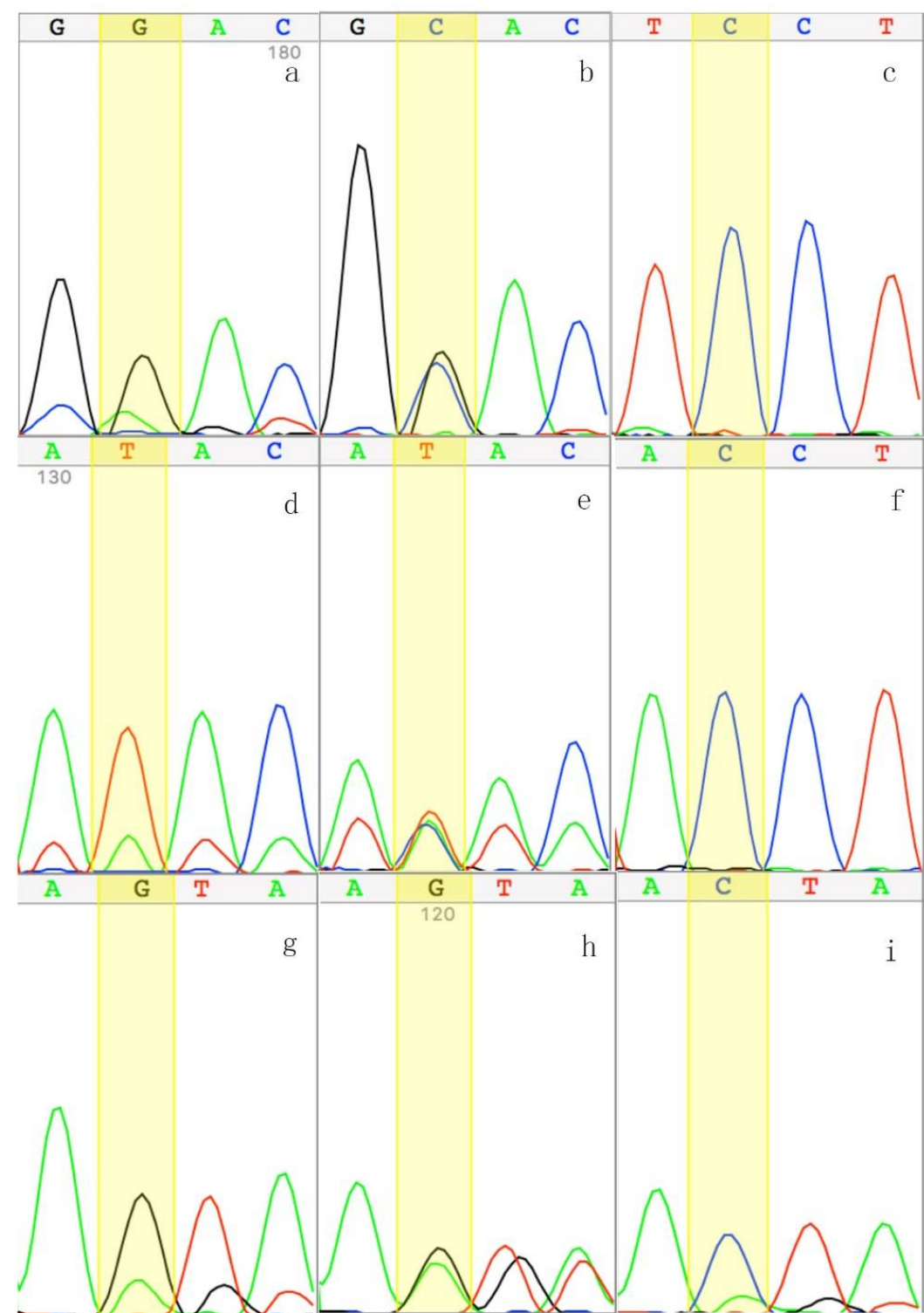

Figure 1: Genotype of SNP 3127 site. a: Genotype of SNP 3127 site: CC; $b$ : Genotype of SNP 3127 site: GC; c: Genotype of SNP 3127 site: GG; d: Genotype of SNP 3172 site: AA; e: Genotype of SNP 3172 site: AG; f: Genotype of SNP 3172 site: GG; g: Genotype of SNP 3181 site: CC; $h$ : Genotype of SNP 3181 site: CG; i: Genotype of SNP 3181 site: GG. The yellow area means the mutation location

Comparison of HLA-G 3-UTR SNP 3127 genotype and allele frequencies

Comparison of HLA-G 3-UTR SNP 3127 genotype and allele frequencies of pregnant women from the two groups

In HLA-G 3-UTR 3127 site, two alleles G and C, and three genotypes $C G, C C$ and $G G$ existed. The frequency of site $G$ allele in HLA-G 3-UTR 3127 in the preeclampsia group was $47.2 \%$ and the $\mathrm{C}$ allele frequency was $52.8 \%$. G allele frequency in normal pregnancy group was 52.0 $\%$, while the C allele frequency was $48.0 \%$. There was no significant difference in the $C$ and $G$ allele distribution between the two groups $(p>$ 0.05). HLA-G 3-UTR 3127 site CG genotype frequency in the preeclampsia group was 45.3 $\%$, which was significantly lower than that in the normal pregnancy group $(64.7 \%, p>0.05$, Table 2).

Comparison of embryo HLA-G 3-UTR SNP 3127 genotype and allele frequencies from the two groups

Two alleles were found in HLA-G 3-UTR 3127 site: $G$ and $C$, as well as 3 genotypes: CG, CC and $G G$. The frequency distributions of these alleles and genotypes are shown in Table 3. In the preeclampsia group, $G$ allele frequency was $46.9 \%$, while the $C$ allele frequency was $53.1 \%$. The $G$ allele frequency in normal pregnancy group was $45.1 \%$ while the C allele frequency 
was $54.9 \%$. No significant difference in the two allele frequencies was found between the two groups $\left(x^{2}=0.044, p=0.833>0.05\right)$. In addition, no significant difference in genotype distribution frequencies was found between the two groups $(p>0.05)$.
Comparison of mother/embryo HLA-G 3-UTR SNP 3127 compatible genotype between the two groups

There was no significant difference in mother/ embryo HLA-G 3-UTR SNP 3127 compatible genotype between the two groups $(p>0.05$, Table 4).

Table 2: Comparison of HLA-G 3-UTR 3127 SNP between preeclampsia group and normal pregnancy group

\begin{tabular}{|c|c|c|c|c|c|c|}
\hline \multirow{2}{*}{ HLA-G } & \multicolumn{2}{|c|}{$\begin{array}{l}\text { Preeclampsia group } \\
\qquad(\mathrm{n}=53)\end{array}$} & \multicolumn{2}{|c|}{$\begin{array}{l}\text { Normal pregnancy group } \\
(\mathrm{n}=51)\end{array}$} & \multirow{2}{*}{$x^{2}$} & \multirow{2}{*}{$P$} \\
\hline & $N$ & $\begin{array}{c}\text { Frequency } \\
\text { (\%) }\end{array}$ & $N$ & $\begin{array}{c}\text { Frequency } \\
\text { (\%) }\end{array}$ & & \\
\hline \multicolumn{7}{|l|}{ Allele } \\
\hline C & 56 & 52.8 & 49 & 48.0 & & \\
\hline G & 50 & 47.2 & 53 & 52.0 & 0.477 & 0.490 \\
\hline $\begin{array}{l}\text { Summation } \\
\text { genotype }\end{array}$ & 106 & 100 & 102 & 100 & & \\
\hline CC & 16 & 30.2 & 8 & 15.9 & 3.079 & 0.079 \\
\hline CG & 24 & 45.3 & 33 & 64.7 & 3.959 & 0.047 \\
\hline $\mathrm{GG}$ & 13 & 24.5 & 10 & 19.6 & 0.365 & 0.546 \\
\hline Summation & 53 & 100 & 51 & 100 & & \\
\hline
\end{tabular}

Table 3: Comparison of HLA-G 3-UTR 3127 SNP in embryo of the preeclampsia and normal pregnancy groups

\begin{tabular}{|c|c|c|c|c|c|c|}
\hline \multirow[t]{2}{*}{ HLA-G } & \multicolumn{2}{|c|}{$\begin{array}{l}\text { Preeclampsia group } \\
\qquad(n=32)\end{array}$} & \multicolumn{2}{|c|}{$\begin{array}{c}\text { Normal pregnancy group } \\
(n=41)\end{array}$} & \multirow{2}{*}{$x^{2}$} & \multirow[t]{2}{*}{$\mathbf{P}$} \\
\hline & $N$ & Frequency(\%) & $N$ & Frequency(\%) & & \\
\hline \multicolumn{7}{|l|}{ Allele } \\
\hline C & 34 & 53.1 & 45 & 54.9 & & \\
\hline G & 30 & 46.9 & 37 & 45.1 & 0.044 & 0.833 \\
\hline $\begin{array}{l}\text { Summation } \\
\text { genotype }\end{array}$ & 64 & 100 & 82 & 100 & & \\
\hline CC & 7 & 21.9 & 9 & 22.0 & 0.000 & 0.994 \\
\hline CG & 20 & 62.5 & 27 & 65.9 & 0.088 & 0.767 \\
\hline GG & 5 & 15.6 & 5 & 12.1 & 0.006 & $0.936^{*}$ \\
\hline Summation & 32 & 100 & 41 & 100 & & \\
\hline
\end{tabular}

Table 4: Analysis of mother/embryo HLA-G 3-UTR 3127 SNP compatible genotype frequencies in the preeclampsia and normal pregnancy groups

\begin{tabular}{|c|c|c|c|c|c|c|c|}
\hline \multirow{2}{*}{$\begin{array}{l}\text { Mother } \\
\text { compatible } \\
\text { genotype }\end{array}$} & \multirow{2}{*}{$\begin{array}{l}\text { Embryo } \\
\text { compatible } \\
\text { genotype }\end{array}$} & \multicolumn{2}{|c|}{$\begin{array}{c}\text { Preeclampsia } \\
\text { group } \\
(\mathrm{n}=\mathbf{2 7}) \\
\end{array}$} & \multicolumn{2}{|c|}{$\begin{array}{c}\text { Normal } \\
\text { pregnancy } \\
(\mathrm{n}=35)\end{array}$} & \multirow[t]{2}{*}{$x^{2}$} & \multirow[t]{2}{*}{$P$} \\
\hline & & $N$ & $\begin{array}{c}\text { Frequency } \\
\text { (\%) }\end{array}$ & $N$ & $\begin{array}{l}\text { Frequency } \\
\text { (\%) }\end{array}$ & & \\
\hline \multirow[t]{3}{*}{$\mathrm{CC}$} & CC & 2 & 7.4 & 1 & 2.9 & 0.685 & 0.408 \\
\hline & CG & 7 & 25.9 & 2 & 5.7 & 3.521 & $0.061^{\star}$ \\
\hline & GG & 1 & 3.7 & 0 & 0 & -- & $0.435^{\#}$ \\
\hline \multirow[t]{3}{*}{ CG } & $\mathrm{CC}$ & 1 & 3.7 & 6 & 17.1 & 1.571 & $0.210^{\star}$ \\
\hline & CG & 8 & 29.6 & 16 & 45.7 & 1.662 & 0.197 \\
\hline & GG & 1 & 3.7 & 2 & 5.7 & 0.000 & $1.000^{\circ}$ \\
\hline \multirow[t]{3}{*}{ GG } & $\mathrm{CC}$ & 2 & 7.4 & 1 & 2.9 & 0.053 & $0.817^{*}$ \\
\hline & CG & 5 & 18.5 & 5 & 14.3 & 0.010 & $0.919^{*}$ \\
\hline & GG & 1 & 3.7 & 1 & 2.9 & -- & $1.000^{\#}$ \\
\hline
\end{tabular}

\# With definite probability methods; ${ }^{*}$ with corrective Chi-Square test 
Comparison of HLA-G 3-UTR 3172 genotype and allele frequencies

Comparison of HLA-G 3-UTR SNP 3172 genotype and allele frequencies of pregnant women from the two groups

In HLA-G 3-UTR 3172 site, two alleles ( $G$ and $A$ ), and three genotypes ( $A G, A A$ and $G G$ ) were present. The $G$ allele frequencies in the preeclampsia and normal pregnancy groups were 42.5 and $36.3 \%$, respectively, while the A allele frequencies in the preeclampsia and normal pregnancy groups were 57.5 and $63.7 \%$, respectively. Between the two groups, no significant differences were found $\left(x^{2}=0.831, p\right.$ $=0.362>0.05)$. The frequency of AA genotype in the preeclampsia group $(50.9 \%)$ was significantly higher than that in the normal pregnancy group $(25.5 \%, p<0.05$; Table 5$)$.

Comparison of HLA-G 3-UTR SNP 3172 genotype and allele frequencies of embryo from the two groups

In HLA-G 3-UTR 3172 site, two alleles: $G$ and A; and three genotypes: $A G, A A$ and $G G$ were present. The frequencies of $G$ allele in the preeclampsia and normal pregnancy groups were 45.3 and $43.9 \%$, respectively. The frequencies of the $A$ allele in the preeclampsia and normal pregnancy groups were 54.7 and $56.1 \%$, respectively. There were no significant differences in allele frequencies between the two groups $(p>0.05)$. Moreover, there were no significant differences in genotype distribution frequencies between the two groups $(p>0.05$, Table 6).

Comparison of mother/ embryo HLA-G 3-UTR SNP 3172 compatible genotype between the two groups

The frequency of compatible AA/AA genotype frequency of mother/ embryo HLA-G 3-UTR 3172 site in the preeclampsia group (55.6\%) was significantly higher $(p<0.05)$ than that in the normal pregnancy group $(28.6 \%$, Table 7$)$.

Comparison of HLA-G 3-UTR SNP 3181 genotype and allele frequencies

Comparison of HLA-G 3-UTR SNP 3181 Genotype and allele frequencies of pregnant women from the two groups

There were 2 alleles $(G \& C)$ and 3 genotypes (CG, CC \& GG) in HLA-G 3-UTR 3181 site.

Table 5: Comparison of HLA-G 3-UTR 3172 SNP of pregnant women between preeclampsia and normal pregnancy groups

\begin{tabular}{|c|c|c|c|c|c|c|}
\hline \multirow[t]{2}{*}{ HLA-G } & \multicolumn{2}{|c|}{$\begin{array}{l}\text { Preeclampsia group } \\
(n=53)\end{array}$} & \multicolumn{2}{|c|}{$\begin{array}{l}\text { Normal pregnancy group } \\
(\mathrm{n}=51)\end{array}$} & \multirow[t]{2}{*}{$x^{2}$} & \multirow[t]{2}{*}{$P$} \\
\hline & $N$ & Frequency (\%) & $N$ & Frequency (\%) & & \\
\hline \multicolumn{7}{|l|}{ Allele } \\
\hline A & 61 & 57.5 & 65 & 63.7 & & \\
\hline G & 45 & 42.5 & 37 & 36.3 & 0.831 & 0.362 \\
\hline $\begin{array}{l}\text { Summation } \\
\text { genotype }\end{array}$ & 106 & 100 & 102 & 100 & & \\
\hline AA & 27 & 50.9 & 13 & 25.5 & 7.114 & 0.008 \\
\hline AG & 17 & 32.1 & 21 & 41.2 & 0.928 & 0.335 \\
\hline GG & 9 & 17.0 & 17 & 33.3 & 3.706 & 0.054 \\
\hline Summation & 53 & 100 & 51 & 100 & & \\
\hline
\end{tabular}

Table 6: Comparison of embryo HLA-G 3-UTR 3172 SNP between the preeclampsia and normal pregnancy groups

\begin{tabular}{|c|c|c|c|c|c|c|}
\hline \multirow[t]{2}{*}{ HLA-G } & \multicolumn{2}{|c|}{$\begin{array}{l}\text { Preeclampsia group } \\
(n=32)\end{array}$} & \multicolumn{2}{|c|}{$\begin{array}{l}\text { Normal pregnancy group } \\
(\mathrm{n}=41)\end{array}$} & \multirow[t]{2}{*}{$x^{2}$} & \multirow[t]{2}{*}{$P$} \\
\hline & $N$ & Frequency (\%) & $N$ & Frequency (\%) & & \\
\hline \multicolumn{7}{|l|}{ Allele } \\
\hline A & 35 & 54.7 & 46 & 56.1 & & \\
\hline G & 29 & 45.3 & 36 & 43.9 & 0.029 & 0.865 \\
\hline $\begin{array}{l}\text { Summation } \\
\text { Genotype }\end{array}$ & 64 & 100 & 82 & 100 & & \\
\hline$A A$ & 7 & 21.9 & 11 & 26.9 & 0.237 & 0.626 \\
\hline$A G$ & 21 & 65.6 & 24 & 58.5 & 0.382 & 0.537 \\
\hline GG & 4 & 12.5 & 6 & 14.6 & 0.000 & $1.000^{\circ}$ \\
\hline Summation & 32 & 100 & 41 & 100 & & \\
\hline
\end{tabular}

* With corrective Chi-Square test 
Table 7: Analysis of mother/ embryo HLA-G 3-UTR 3172 SNP compatible genotype frequencies

\begin{tabular}{|c|c|c|c|c|c|c|c|}
\hline \multirow{2}{*}{$\begin{array}{l}\text { Mother } \\
\text { compatible } \\
\text { genotype }\end{array}$} & \multirow{2}{*}{$\begin{array}{c}\text { Embryo } \\
\text { compatible } \\
\text { genotype }\end{array}$} & \multicolumn{2}{|c|}{$\begin{array}{l}\text { Preeclampsia group } \\
(\mathrm{n}=27)\end{array}$} & \multicolumn{2}{|c|}{$\begin{array}{c}\text { Normal pregnancy } \\
\text { group }(n=35)\end{array}$} & \multirow{2}{*}{$x^{2}$} & \multirow{2}{*}{$\boldsymbol{P}$} \\
\hline & & $N$ & $\begin{array}{l}\text { Frequency } \\
\text { (\%) }\end{array}$ & $N$ & $\begin{array}{l}\text { Frequency } \\
\text { (\%) }\end{array}$ & & \\
\hline \multirow[t]{3}{*}{$\overline{A A}$} & $\overline{A A}$ & 15 & 55.6 & 10 & 28.6 & 4.612 & 0.032 \\
\hline & $A G$ & 1 & 3.7 & 7 & 20.0 & 2.298 & $0.130^{\star}$ \\
\hline & GG & 2 & 7.4 & 1 & 2.9 & 0.053 & $0.817^{\pi}$ \\
\hline \multirow[t]{3}{*}{$A G$} & $\mathrm{AA}$ & 2 & 14.8 & 3 & 8.6 & 0.134 & $0.715^{\circ}$ \\
\hline & $A G$ & 2 & 7.4 & 5 & 14.3 & 0.197 & $0.657^{\circ}$ \\
\hline & GG & 1 & 3.7 & 4 & 11.4 & 0.406 & 0.524 \\
\hline \multirow[t]{3}{*}{ GG } & $A A$ & 0 & 0 & 1 & 2.9 & -- & $1.000^{\#}$ \\
\hline & $A G$ & 3 & 11.1 & 4 & 11.4 & 0.000 & $1.000^{\circ}$ \\
\hline & $\mathrm{GG}$ & 1 & 3.7 & 0 & 0 & -- & $0.435^{\#}$ \\
\hline
\end{tabular}

\# With definite probability method; ${ }^{*}$ with corrective Chi-square test

No significant difference in $G$ allele frequencies was found between the preeclampsia group $(33.0 \%)$ and the normal pregnancy group $(36.3 \%, p>0.05)$. Similarly, there was no significant difference in $\mathrm{C}$ allele frequency between the normal pregnancy group (63.7\%) and the $C$ allele frequency in the preeclampsia group $(67.0 \%, p>0.05$; Table 8$)$.
Comparison of HLA-G 3-UTR SNP 3181 genotype and allele frequencies in embryos from the two groups

The $G$ allele frequencies in embryos in the preeclampsia and normal pregnancy groups were 20.7 and $34.1 \%$, respectively, while the corresponding frequencies of the $\mathrm{C}$ allele were 57.3 and $65.9 \%$, respectively $(p>0.05$; Table 9).

Table 8: Comparison of HLA-G 3-UTR 3181 SNP of pregnant women between the preeclampsia and normal pregnancy groups

\begin{tabular}{|c|c|c|c|c|c|c|}
\hline \multirow[t]{2}{*}{ HLA-G } & \multicolumn{2}{|c|}{$\begin{array}{l}\text { Preeclampsia group } \\
(n=53)\end{array}$} & \multicolumn{2}{|c|}{$\begin{array}{c}\text { Normal pregnancy group } \\
(\mathrm{n}=51)\end{array}$} & \multirow[t]{2}{*}{$x^{2}$} & \multirow[t]{2}{*}{$P$} \\
\hline & $N$ & Frequency (\%) & $N$ & Frequency (\%) & & \\
\hline \multicolumn{7}{|l|}{ Allele } \\
\hline C & 71 & 67.0 & 65 & 63.7 & & \\
\hline G & 35 & 33.0 & 37 & 36.3 & 0.243 & 0.622 \\
\hline $\begin{array}{l}\text { Summation } \\
\text { genotype }\end{array}$ & 106 & 100 & 102 & 100 & & \\
\hline CC & 22 & 41.5 & 17 & 33.3 & 0.741 & 0.389 \\
\hline CG & 27 & 50.9 & 31 & 60.8 & 1.020 & 0.312 \\
\hline & 4 & 7.6 & 3 & 5.9 & 0.00 & $1.000^{\circ}$ \\
\hline Summation & 53 & 100 & 51 & 100 & & \\
\hline
\end{tabular}

Table 9: Comparison of embryo HLA-G 3-UTR 3181 SNP between the preeclampsia and normal pregnancy groups

\begin{tabular}{|c|c|c|c|c|c|c|}
\hline \multirow[t]{2}{*}{ HLA-G } & \multicolumn{2}{|c|}{$\begin{array}{l}\text { Preeclampsia group } \\
(n=32)\end{array}$} & \multicolumn{2}{|c|}{$\begin{array}{l}\text { Normal pregnancy group } \\
(\mathrm{n}=41)\end{array}$} & \multirow[t]{2}{*}{$x^{2}$} & \multirow[t]{2}{*}{$\boldsymbol{P}$} \\
\hline & $N$ & Frequency (\%) & $N$ & Frequency (\%) & & \\
\hline Allele & & & & & & \\
\hline $\mathrm{C}$ & 47 & 57.3 & 54 & 65.9 & & \\
\hline G & 17 & 20.7 & 28 & 34.1 & 0.970 & 0.865 \\
\hline $\begin{array}{l}\text { Summation } \\
\text { genotype }\end{array}$ & 64 & 100 & 82 & 100 & & \\
\hline CC & 15 & 46.9 & 15 & 36.6 & 0.786 & 0.375 \\
\hline CG & 17 & 53.1 & 24 & 58.5 & 0.214 & 0.644 \\
\hline GG & 0 & 0 & 2 & 4.9 & & $1.000^{\#}$ \\
\hline Summation & 32 & 100 & 41 & 100 & & \\
\hline
\end{tabular}

* With corrective Chi-square test 
Table 10: Analysis of frequencies of mother/ embryo HLA-G 3-UTR 3181 SNP compatible genotype

\begin{tabular}{|c|c|c|c|c|c|c|c|}
\hline \multirow{2}{*}{$\begin{array}{l}\text { Mother } \\
\text { compati } \\
\text { ble } \\
\text { genotyp } \\
\text { e }\end{array}$} & \multirow{2}{*}{$\begin{array}{c}\text { Embryo } \\
\text { compatibl } \\
\text { e } \\
\text { genotype }\end{array}$} & \multicolumn{2}{|c|}{$\begin{array}{l}\text { Preeclampsia } \\
\text { group }(n=27)\end{array}$} & \multicolumn{2}{|c|}{$\begin{array}{c}\text { Normal pregnancy } \\
\text { group }(n=35)\end{array}$} & \multirow[b]{2}{*}{$x^{2}$} & \multirow[b]{2}{*}{$P$} \\
\hline & & $N$ & $\begin{array}{l}\text { Frequency } \\
\text { (\%) }\end{array}$ & $N$ & $\begin{array}{l}\text { Frequenc } \\
y(\%)\end{array}$ & & \\
\hline \multirow[t]{3}{*}{$\mathrm{CC}$} & $\mathrm{CC}$ & 5 & 18.5 & 5 & 14.3 & 0.010 & $\overline{0.919}$ \\
\hline & CG & 9 & 33.3 & 5 & 14.3 & 3.163 & 0.075 \\
\hline & GG & 0 & 0 & 1 & 2.9 & -- & $1.000^{\#}$ \\
\hline \multirow[t]{3}{*}{$C G$} & $\mathrm{CC}$ & 7 & 25.9 & 8 & 22.9 & 0.078 & 0.780 \\
\hline & CG & 4 & 14.8 & 14 & 40.0 & $4, .692$ & 0.030 \\
\hline & GG & 0 & 0 & 0 & 0 & -- & -- \\
\hline \multirow[t]{3}{*}{ GG } & CC & 0 & 0 & 0 & 0 & -- & -- \\
\hline & CG & 2 & 7.4 & 2 & 5.7 & 0.000 & $1.000^{\circ}$ \\
\hline & GG & 0 & 0 & 0 & 0 & -- & -- \\
\hline
\end{tabular}

\# With definite probability methods; ${ }^{*}$ with corrective Chi-square test

Comparison of mother/embryo HLA-G 3-UTR SNP 3181 compatible genotype between the two groups

The frequency of compatible CC/GG genotype in mother/embryo HLA-G 3-UTR 3181 site in the preeclampsia group (14.8\%) was significantly lower than that in normal pregnancy group $(40.0 \%)(p<0.05$; Table 10$)$.

\section{DISCUSSION}

In this study, 3 SNPs were discovered in HLA-G exon 8 3-UTR. The three different SNPs were located in 3127 site (rs1063320), 3172 site (rs9380142) and 3181 site (rs1610696).

This study has demonstrated that the frequency of SNP 3127 site CG genotype in pregnant women with preeclampsia $(45.3 \%)$ was significantly lower than that in normal pregnancy group $(64.7 \%)$. However there was no significant difference in compatible genotype distributions between the two groups. Consequently, it can be concluded that women with CG genotype in HLAG 3-UTR SNP 3127 site have lower risk of preeclampsia. There was no difference in SNP 3127 genotype frequency distributions in newborn between the two groups. This is contrary to the results of Larsen, who reported significant differences in CG genotype distributions between Caucasian preeclampsia and normal pregnancy groups [13]. This difference might be due to the differences in ethnic groups and geographic regions.

The significant difference in AA genotype frequencies between the preeclampsia and normal pregnancy groups is in agreement with the findings of Yie [12]. Since pregnancy is a special physiological state, these results, whether in preeclampsia or normal pregnancy, are most likely due to mother-baby gene interaction. In effect, the pathogenic gene could be from mother or from the embryo. Consequently, combination analysis of compatible genotype between mother and embryo may provide insight into the pathogenesis of preeclampsia. In this study, it was found from analysis of mother/ embryo compatible genotype that the frequencies of mother/ embryo compatible AA/ AA genotype in the preeclampsia group was higher than the frequency in normal pregnancy group. This strongly suggests that HLA-G 3-UTR SNP 3172 may be a pre-disposing gene for preeclampsia, and may increase risk of preeclampsia. However, there were no significant differences in genetic polymorphisms between newborns in the two groups. This is consistent with the results of Larsen [12]. In Caucasian newborn the A allele occurs primarily in normal pregnancy rather than in preeclampsia. Moreover there was no significant difference in HLA-G 3-UTR 3172 genotype between the two groups.

It is believed that HLA-G 3172 site is near to an AUUA motif [12]. The AU motif is a sequence which consists of uridylic acid and some adenosine, a kind of cis-acting degradation signal which can encode cytokines, growth factors and other regulating proteins. It also influences the stability of 3-UTR mRNAs [14, 15]. It has been established that $A$ allele can reduce the stability of HLA-G mRNAs [12]. Therefore mutation in this site reduces the level of mRNA and then causes changes in transcription and translation, leading to decreased HLA-G protein expression. This reduces maternal-fetal immune tolerance, and also reduces physical protective reaction between mother and baby. In addition, it decreases the invasive ability of trophoblast cells. Superficial implantation of placenta causes ischemia and placental hypoxia. 


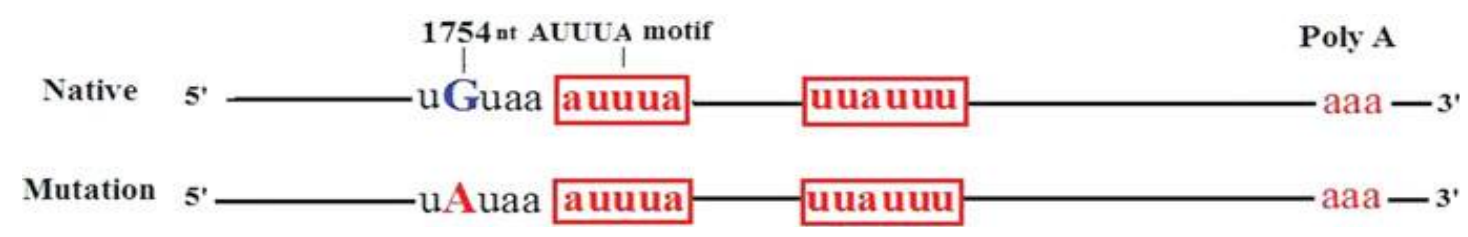

Figure 2: HLA-G mRNA 3'-UTR sequence: 3'-UTR G $\rightarrow$ A near to AU-motif

Oxidative stress and lipid peroxidation arise in local placenta. The cells of intervillous space are activated and endothelium is damaged, all of which ultimately lead to preeclampsia.

The results of this research show no significant difference in HLA-G SNP 3182 polymorphisms between mother and embryo in the two groups. This finding agrees with that of Larsen [13]. In Caucasian newborn, the frequency of $\mathrm{CG} / \mathrm{CG}$ genotype in mother/ embryo 3181 site in the preeclampsia group was lower than that in the normal pregnancy group. This implies that populations with mother/embryo compatible genotype (CG/CG) in HLA-G 3181 site have lower risk of preeclampsia.

However some researchers believe that there is complete linkage disequilibrium between HLA-G 14bp allele and the three SNPs (SNP 2995, SNP 3127 and SNP 3172). SNP 3172 and SNP 3181 are on the right side of AU-motif which is associated with the stability of mRNA. When $14 \mathrm{bp}$ deletion polymorphism is combined with SNP 3127, it is linked to primipara with severe preeclampsia. Research has shown that HLA-G $14 \mathrm{bp}$ deletion polymorphism is a special genotype of exon 8 . When embryo genotype is SNP2995 (C) / SNP3127 (G) / SNP3172 (A) / SNP3181 (G) / +14bp homozygotes, it is associated with primipara with severe preeclampsia. Therefore it is important to study the relationship between HLA-G 3-UTR polymorphism and preeclampsia from linkage dis-equilibrium, analyze the impact of SNP polymorphism near to AU-motif on the stability of mRNA, and the impact of the HLA-G protein expression in the placenta.

\section{CONCLUSION}

This study has demonstrated that there might be a relationship between HLA-G 3-UTR SNP 3172 polymorphism and susceptibility to preeclampsia in China Henan Han population. It has shown that preeclampsia is a disease of abnormal immune tolerance between mother and embryo, and provided new empirical evidence for pathogenesis of the disease. The results also provide an important clue for predicting likelihood of preeclampsia, as well as prospects for gene therapy by analyzing differences in compatible genotype between mother and embryo.

\section{REFERENCES}

1. Le J. Gynecotokology, 7th edn. 2008: People's Medical Publishing House, China

2. Sibai B, Dekker G, Kupferminc M. Pre-eclampsia. Lancet 2005; 365(9461): 785.

3. Redman CW, Sargent IL. Latest advances in understanding preeclampsia. Science 2005; 308(5728): 1592-1594.

4. Saito S, Sakai M, Sasaki Y, Nakashima A, Shiozaki A. Inadequate tolerance induction may induce preeclampsia. J Reprod Immunol 2007; 76(1-2): 30.

5. Mcmaster MT, Librach CL, Zhou Y, Lim KH, Janatpour MJ, Demars R, Kovats S, Damsky C, Fisher SJ. Human placental HLA-G expression is restricted to differentiated cytotrophoblasts. J Immunol 1995; 154(8): 3771-3778.

6. Widschwendter M, Schröcksnadel H, Mörtl MG. Preeclampsia: a disorder of placental mitochondria? Mol Med Today 1998; 4(7): 286-291.

7. Pijnenborg $R$. Implantation and immunology: maternal inflammatory and immune cellular responses to implantation and trophoblast invasion. Reprod Biomed Online 2002; 4 Suppl 3(supplement 3): 14-17.

8. Apps R, Gardner L, Moffett A. A critical look at HLA-G. Trends in Immunology 2008; 29(7): 313-321.

9. O'Brien M, Dausset J, Carosella ED, Moreau P. Analysis of the role of HLA-G in preeclampsia. Hum Immunol 2000; 61(11): 1126-1131.

10. Bhalla A, Stone PR, Liddell HS, Zanderigo A, Chamley $L W$. Comparison of the expression of human leukocyte antigen (HLA)-G and HLA-E in women with normal pregnancy and those with recurrent miscarriage. Reprod 2006; 131(3): 583-589.

11. Yie SM, Li LH, Li YM, Librach C. HLA-G protein concentrations in maternal serum and placental tissue are decreased in preeclampsia. Am J Obstet Gynecol 2004; 191(2): 525-529.

12. World Health Organization. Declaration of Helsinki. BrMedJ1996; 313(7070): 1448-1449.

13. Larsen $M H$, Hylenius $S$, Andersen AMN, Hviid TVF. The 3-untranslated region of the HLA-G gene in relation to pre-eclampsia: revisited. Tissue Antig 2010; 75(3): 253261. 